\title{
Gamification: Blood Donor Apps for iOS Devices
}

\author{
Alvedi Chandra Sabani \\ Computer Science Program \\ Bina Nusantara University \\ Jakarta, Indonesia
}

\author{
Ida Bagus Kerthyayana Manuaba \\ Computer Science Program \\ Bina Nusantara University \\ Jakarta, Indonesia
}

\author{
Erwin Adi \\ Computer Science \\ Edith Cowan University \\ Perth, Australia
}

\begin{abstract}
Humans need blood to live and there is no substitute for it. Based on the statistics gathered by the Australian Red Cross, 1 in 3 people will need a blood donation once in their lifetime. However, only $1.5 \%$ of Indonesian people donate their blood. In order to rectify this unbalanced blood donation supply and demand, an application named Game4Life was developed and tested. This paper aims to implement 'gamification' on $i O S$ devices to encourage users to donate their blood and help to end this shortage. This paper focused on developing features that would help blood donors to schedule their donation as well as a reward and achievement system to motivate future donors and keep them engaged. The deliverable prototype of this paper is implementable and expandable in real life with the cooperation of Palang Merah Indonesia (Red Cross Indonesia) and a company sponsor. Based on the User Acceptance Test results and Palang Merah Indonesia's response, Game4Life has successfully satisfied its scope and requirements.
\end{abstract}

Keywords-Blood donation, blood stock, event calendar, event locator, gamification, hospital enquiry, reward system.

\section{INTRODUCTION}

According to the American Red Cross, the main reason people donate their blood is because of their willingness to help others [1]. However, the supply of blood is a long way from meeting demand. Thus, Palang Merah Indonesia (PMI) and several community-driven groups such as Perhimpunan Donor Darah Indonesia (PDDI) are trying to encourage people to donate their blood in various ways. Some examples of their efforts are conducting donation events, and creating a website whereby users are able to check on blood stock. Palang Merah Indonesia also provides blood donation education as early as elementary school. Despite those efforts, the number of blood donors is still very low which leads to an insufficient blood supply $[2,3]$. Hence, we propose an alternative solution to encourage people donating their blood that hopefully could help end this shortage.

Nowadays, almost everyone has a smartphone and many people are using applications as we can see from the popularities of 'Pokemon Go' [3], especially on iOS devices as one of mobile phone market leaders [4]. Hence, we believe develop an iOS mobile application in order to provide demand form market trends and maximize the project's effectiveness still reasonable.

'Gamification' is the use of game-thinking and game mechanics in a non-game context in order to engage users and solve problems [5]. Gamification is being used in applications to improve user engagement. Gamification techniques can be based on rewarding points to people who share experiences on location-based platforms such as Foursquare and online leader boards or medal achievements on Playstation 3 and Xbox 360 for example [6]. Sometimes they embed small casual games within other activities. Hence, the use of game mechanics to make non-game materials becomes more engaging [7]. Nowadays, developers are trying to gamify everything. Hamaria and Koivistoa [8], stated that the wise use of gamification could become beneficial to society.

The authors' idea is to create an iOS mobile application that motivates people to donate their blood as well as educating them of the importance of blood donation by showing them how many lives they could save, for example. We would like to reward donors with points collected for every donation which are redeemable for rewards in real life such as food vouchers. At the same time donors receive in-game rewards such as unlocking backgrounds and their name up on a leaderboard.

This paper's deliverable is a Game4Life, a functional prototype of a blood donation application, mobile application and web service. Game4Life is built as an iOS application for mobile devices.

The benefits of this deliverable can be seen from four different aspects according to their involvement role, which are: (1) future donors as the main target, Game4Life provides facts about healthy blood donation, frequently asked questions (FAQ) and features to contact hospitals that would help answer their questions and clear any doubts and fears about donating their blood. (2) For current donors, Game4Life provides an easy event locator, event calendar and 'contact hospital' feature for arranging reservations to help them organize their next donation as well as rewarding them for their blood with exchangeable reward points. (3) Palang Merah Indonesia (PMI) will benefit by Game4Life's features such as event calendar, event locator, frequently asked questions and blood stock, acting as $P M I^{\text {'s }}$ medium to spread their information as well as a medium to advertise their event. (4) A reward program would allow a company partner to enhance their public image by committing to a CSR program.

This paper shows the theoretical foundation of the application. This will include a brief summary of gamification and an analysis of the development tools. This paper also 
describes the technology and technical knowledge that is used to develop this mobile application prototype. It also shows the comparison between existing blood donation applications, including the benefits that will be delivered as well as analysis of feature similarities from other applications, including the preliminary survey as the basis for the design requirements. The application design and the logic behind the system will be expressed by using various types of diagrams from the Unified Modeling Language (UML) to have a better understanding of how the system works. This chapter analyzes the results of the system observations including the various testing and implementation results. This is followed by a discussion and conclusion section.

\section{THEORETICAL FOUNDATION}

\section{A. Blood Donation}

Blood is a body fluid that carries nutrients and oxygen to the cells and flushed out metabolic waste; it circulates around the body by the pumping action of the heart. Blood donations happen when someone voluntarily donates their blood for transfusions for others who need it. However, the supply is still low considering 1 in 3 people will need blood in their lives [15].

According to Palang Merah Indonesia there are certain criteria for blood donors which are that they have to be healthy, they must have no diseases such as HIV or hepatitis. They must be 17 to 60 years old and have a minimum weight of 45 kilograms [16]. Once donors donate their blood, they have to wait a minimum of 3 months before re-donating their blood [16].

\section{B. Gamification}

Gamification is the use of game thinking and game mechanics in a non-game context in order to engage users and solve problems. Gamification keeps users or gamers engaged in a game and keep playing the game [9]. Fun is the most essential part of gamification, fun drives people to keep doing something and gamification is a fun way to engage user. Fig.1 below is an explanation from Hamari et. al. [9].

Based on Fig. 1 there are 4 different areas divided by a vertical axis which separate games from playing and a horizontal axis which separate whole and partial. When it is the whole thing and its tangible to play we called it a toy. When it is not the whole thing to play like toys but it is still tangible and people could have some fun (like a coloring book) we call it a 'playful design'. On the other hand when it is made purely for playing and having fun we call it 'a game' or 'a serious game'.

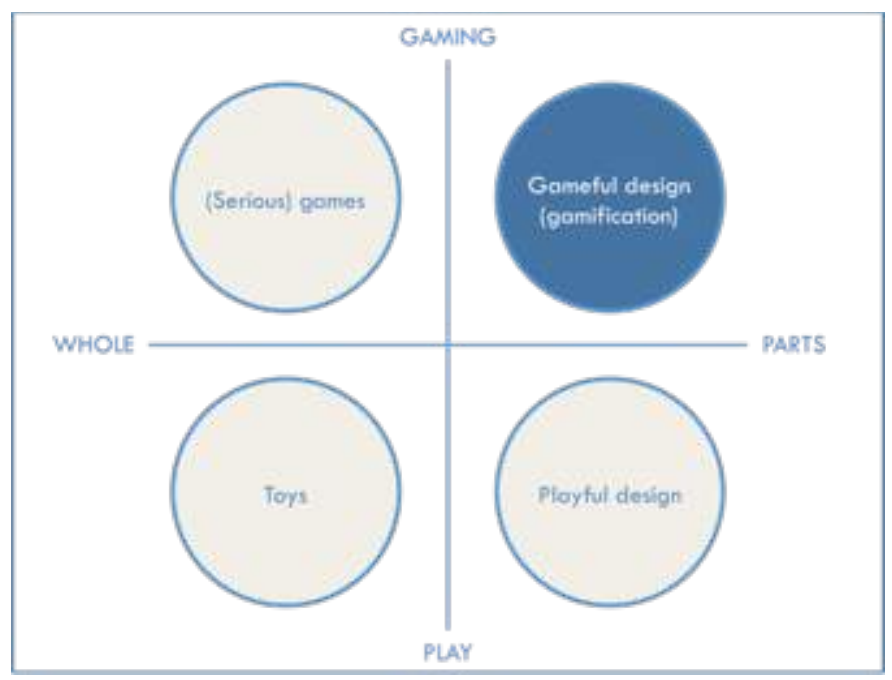

Fig. 1. Gamification Definition [10]

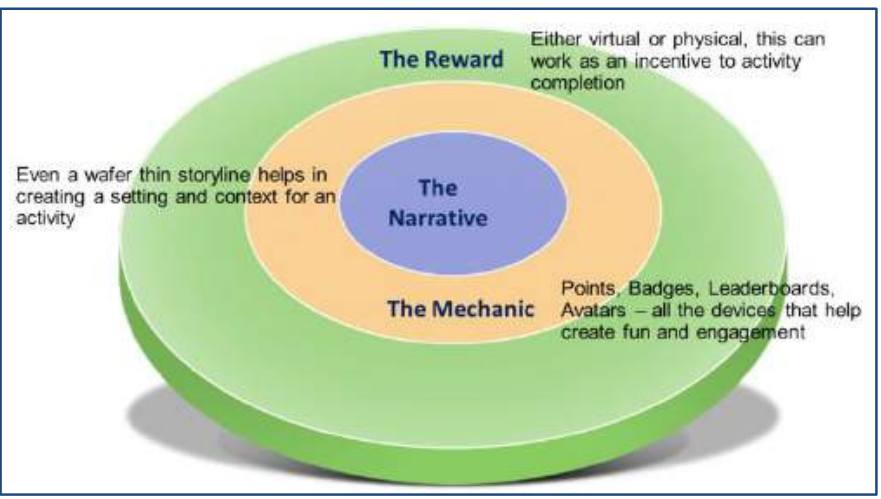

Fig. 2. Gamification Intervention [11]

There are 3 mechanims need to be implemented when using gamification, which are narrative, mechanic, and reward. Based on Fig. 2, the narrative is the storyline or the background of the application. In this case Game4Life is created to encourage users to donate their blood for the first time and regularly donate their blood in a certain period of time as well as providing blood donations an organizer for donors. The mechanic uses gamification features such as points, badges, leaderboards, lives saved, and medals. The rewards could be physical or virtual and Game4Life has both; those rewards could be redeemed by exchanging users points for blood donations. Physical rewards could be food vouchers while virtual rewards could be a WIFI password. 


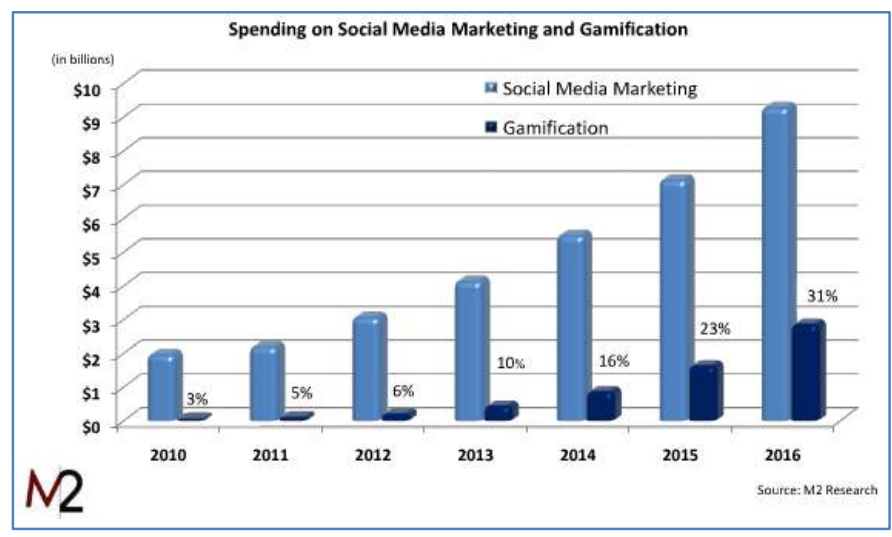

Fig. 3. Gamification Cost Spending [12]

Based on the analysis chart conducted by M2 Research in Fig. 3, it can be seen that since 2010 gamification has growth compared with social media marketing as well as the total amount of dollars.

\section{Operating System iOS}

iOS is a mobile operating system from Apple Inc. It was originally released as iPhone OS in 2007. iOS is an exclusive operating system preinstalled to all Apple devices such as iPhone, iPad, iPod Touch and Apple TV. This exclusive operating system is only released for Apple devices. The development is exclusive to XCode on Mac OS which is only available for Apple computers. According to Apple, iOS has more than 2,000,000 applications available on Apple AppStore [14]. Since iOS version 5, users can update the operating system right away from the device without the need of a computer. The current version is iOS version 9 .

\section{EXISTING SOLUTIONS}

Medical science is growing and more diseases can be cured, with earlier detection, better medicine, therapy, and operations, but more blood transfusions are needed. There is no substitution for blood [17] but the supply of blood is never enough. Many organizations have been trying their best efforts to gather blood from all around the world. In Indonesia Palang Merah Indonesia runs the blood donation program. Figure 4 below shows the steps for donating blood.
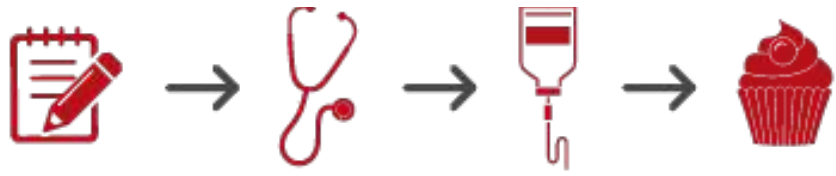

Fig. 4. Four steps of donating blod: medical history, mini physical, donation and snack.

The human population keeps increasing, and more patients need blood every day. According to the Australian Red Cross, 1 in 3 people need blood once in their lives but only 1 in 30 people donate blood [17]. That condition is even worse in Indonesia, considering Indonesia ranks fourth most populous country after China, India and the United States. However, only $1.5 \%$ of Indonesian donate their blood, far below World Health Organization (WHO) standards [2]. Neighboring countries such as Singapore and Malaysia have 4\% blood donors from the total population and United States has 7\% [2].

Palang Merah Indonesia has targeted 100 blood donation cars. Palang Merah Indonesia has more than 80 cars [2]. PMI said that "the blood of the nation is healthy and make donors even healthier" [2]. Despite all of their efforts, the blood donation rate is still low and demand is not yet satisfied. Thus, the authors felt responsible to help solve this shortage. Based on observations, large numbers of Indonesian people always follow mobile phone trends. They keep changing from one phone to another especially when new phones are released.

There are many mobile applications available. Apple iOS had more than 2,000,000 applications available on their AppStore by June 2016 [13]. Despite those numbers, only small numbers of applications are made to support blood donation. Below are analyses and comparisons with existing blood donation applications, even though none of them have gamification as a reward program. Some of those applications are:

\section{A. NZ Blood}

NZ Blood (New Zealand Blood) is a free New Zealand blood donation scheduler developed by Dialogue Marketing Inc [20]. According to its official website, it has features: (1) Search for a donor center or mobile blood drive, (2) Schedule an appointment, (3) Reschedule or cancel an appointment, (4) Register as a new donor (5) Change password, (6) View and modify profile, and (6) View appointment and donation history. This application is free and available for both iPhone with iOS 4.3 and above; and Android version 2.2 and above.

\section{B. $3 N C B B$}

NCBB stands for Nebraska Community Blood Bank; this is a free mobile application for both iPhone and Android [20]. This application is also developed by Dialogue Marketing Inc. This is exactly the same application and user interface as NZ Blood. The only difference is this application is it is designed for use in Nebraska instead of New Zealand.

\section{BloodyHelp}

Bloody Help is a paid mobile application developed by Shimon Maman for both iOS and Android. A free version for limited search features is available. This application basically connects donors and patients. When donors are about to donate their blood, they register and put their contact number with blood type, and the system then stores the information on a database. When a patient or relative needs blood, they register and search according to needed blood type, and then the system will give the search result based on nearest location [21].

\section{Blood Donation}

Blood Donation is a free mobile application for both $\mathrm{iOS}$ and Android created by E2M [22]. This application has the ability to search for donations by searching hospital addresses.

\section{E. BloodBuddy}

BloodBuddy is a free iOS application designed for the user to keep track of their blood donation and works as a reminder for the next donation. Donors submit the date of their last 
donation to the application and in the next 3 months this application will alert the donor to re-donate their blood [23].

\section{F. SG Blood}

SG Blood is a blood donation event locator in Singapore. This application is available for iPhone and it is free [24]. There are a few features available within this application; they are: (a) Event locator with date and information details; (b) Map for event address; (c) Blood stock checker; (d) Next donation calculator; and (e) Frequently Asked Questions.

Based on the advantages and disadvantages from existing applications above, it can be concluded that there is no application that actually encourages user to donate their blood for the first time or aims for more donors. Rather all of them are designed to help existing donors to schedule their next donation, instead of actually finding new donors. Game4Life is designed for both existing donors and future donors. By implementing gamification, Game4Life engages existing donors to schedule their next donation while having fun collecting redeemable points for rewards and at the same time it encourages future donors to donate their blood for the first time by informing them of the importance of blood donation and helping them to arrange their first donation whether from the event locator or at a hospital. Once they donated their blood automatically they join the program where they get points for rewards and get their name on a leaderboard.

Most gamification implementation is used for commercial purposes such as Facebook games where users want to top a leaderboard, and in which to get game credit they need to purchase it using their credit card. Game4Life implements gamification for social purposes and does not involve paying money.

There are various types of gamification, Game4Life implements a leaderboard, high scores and a reward program in order to engage donors and appreciate them. Game4Life also compiles essential features from those analyzed applications with its unique one as event locator, event calendar, contact hospital and next donation calculator to maximize helping blood donors and future donors in organizing their donation schedule. The event locator is integrated with GPS providing a map to the destination and calculating a route from current location. It also has a reservation system, hospital inquiries, and the ability to contact developers when they are encountering problems or have something to ask. It also shows how many patients are saved as one donation could save 3 lives [1] along with progressive medal achievements and in-game rewards such as unlocking backgrounds.

\section{A. Preliminary Survey}

The primary survey was conducted from 23 rd to 28 th of February. The main objective of the primary survey was to gather user input before developing the application. As we are targeting users to use the mobile application, it is the best decision to maximize result effectiveness by listening to their suggestions for the deliverable prototype. There were 6 questions as a preliminary survey that was distributed to 120 people randomly and as result there were 94 respondents. Below are the results of the survey:
We found that more than $70 \%$ of respondents are not blood donors, thus Game4Life is focusing to encourage non-donors The survey result also shows most respondent think that it is a tedious process to arrange blood donation in the hospital, thus Game4Life is providing an automated mail feature to contact hospitals where people could donate their blood. This feature aims to encourage them to contact nearby hospitals any time they have an enquiry about blood donation as well as to arrange reservations when necessary. The survey also shows most respondents found that it is not easy to find a blood donation event. Most of the time they do not have enough time to prepare themselves for the blood donation, they need prior notice. Hence Game4Life is providing event locator features to help them by locating the event and calculating the route guide using GPS for their convenience.

We also found that hygiene is an issue. This survey presents that it is important for people to have decent knowledge on blood donation and its proccess. From this fact, Game4Life is creating a Frequently Asked Questions (FAQ) feature to help answer their questions about blood donation. This FAQ feature is made in the English and Indonesian languages.

Based on this preliminary survey, we also found that most of the respondents agreed that blood donors should be rewarded. This survey also verified that the reward system also encourages people to donate their blood. Thus it can be concluded that implementing gamification to engage users and encourage them to donate blood donation is a viable approach.

\section{SYSTEM DESIGN}

\section{A. System Architecture}

Fig. 5 below is the system architecture of Game4Life divided into four different layers:

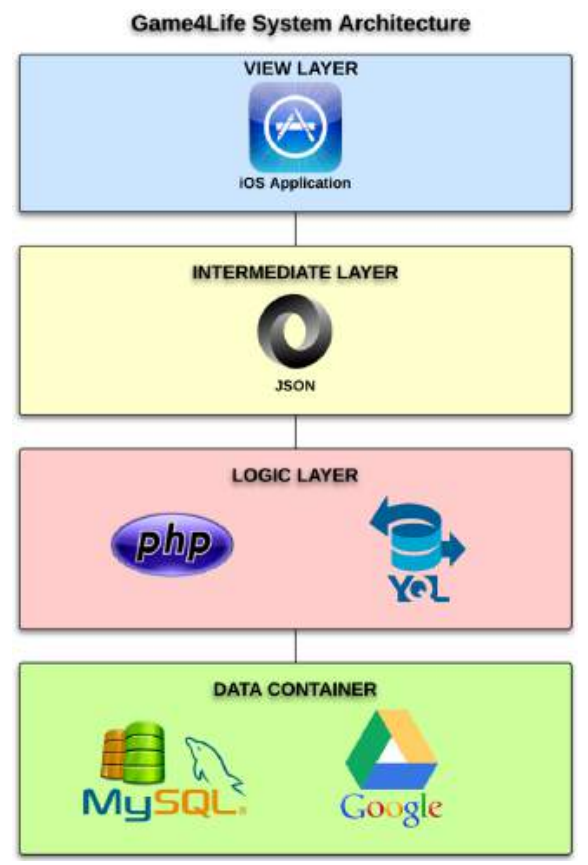

Fig. 5. Game4Life System Architecture. 
As can be seen from Fig. 5, each layer has a different responsibility and components. (1) View Layer. In Game4Life the component of view layer is the end result which is the iOS application itself and the end user interface. The view layer handles the graphical user interface and data presentation. The data is being sent from the Logic Layer through JSON on the intermediate layer. (2) Intermediate Layer. JSON on the intermediate layer acts as a data parser between the end user application and back end web service. It is a medium for the view layer and the logic layer to communicate. (3) Logic Layer. The logic layer is the back-end system which handles core function logic. The logic layer is the only one to communicate straight to data storage and process them respectively to its function. (4) Data Container. The data container is the storage where the data is located. Game4Life has two types of data storage. There is a MySQL database which can be accessed and processed by PHP and Google Drive Spreadsheet.

\section{B. Database Design}

Fig. 6 below is the database design for this application prototype.

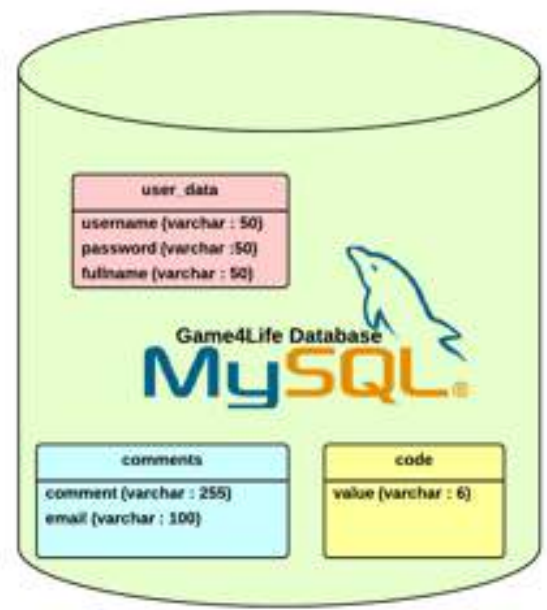

Fig. 6. Game4Life Database Architecture.

\section{Interface Design}

The design of the application is based on a hospital theme where there are sick patients with doctor and nurse. Every time a user donates their blood and receives their code. By submitting the code to the system, users will earn credit for reward exchange as well as points to unlock achievements. To have a clearer idea on the mobile application, the application breakdown as Table 1 below:
Table 1. Application Breakdown [27]

\begin{tabular}{|c|c|c|}
\hline \multicolumn{3}{|c|}{ App Breakdown } \\
\hline Option & Funtion & Description \\
\hline Schedule a Donation & - Scheduler/Aps tatry point & $\begin{array}{l}\text { Lets users xhedule a conation at, a particisoting } \\
\text { bloos clinic. }\end{array}$ \\
\hline See Whol Sweds & $\begin{array}{l}\text { - Intringic reinforcementfor those } \\
\text { motivated by wanting to be heloful } \\
\text { - Donation trequency multipler } \\
\text { - Wra potantial }\end{array}$ & 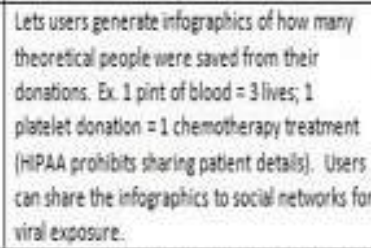 \\
\hline Vat the Hospital & $\begin{array}{l}\text { - Intringic reinforcementfor those } \\
\text { motivated by farily friends needing } \\
\text { donabsens } \\
\text { - Donabon frepseny mukplies }\end{array}$ & 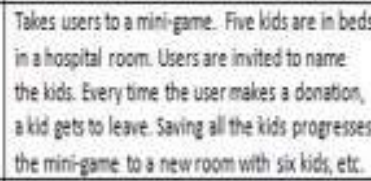 \\
\hline Path to Mr Stoff & 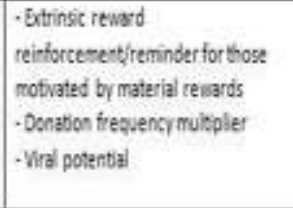 & 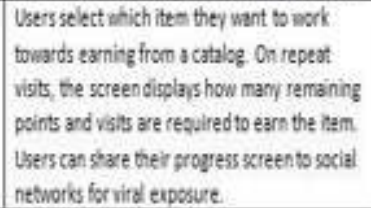 \\
\hline
\end{tabular}

\section{Gamification Implementation}

As mentioned previously in the background, the main idea of implementing gamification is to motivate people donating their blood. The implementation of gamification is done by showing users how many lives they have saved, their achievements and a reward program. The basic idea of gamification on this application is to engage users in donating their blood regularly. For every donation, they will receive code to submit to earn points. The points are applied for physical rewards as food coupons and in game rewards as achievements.

\section{E. Achievement}

Achievement is way of gamification by awarding a nonphysical in-game reward. Several achievements will be implemented on Game4Life as follows:

Medals are given according to how many points they have earned, Fig. 7 below shows all the Game4Life medals.

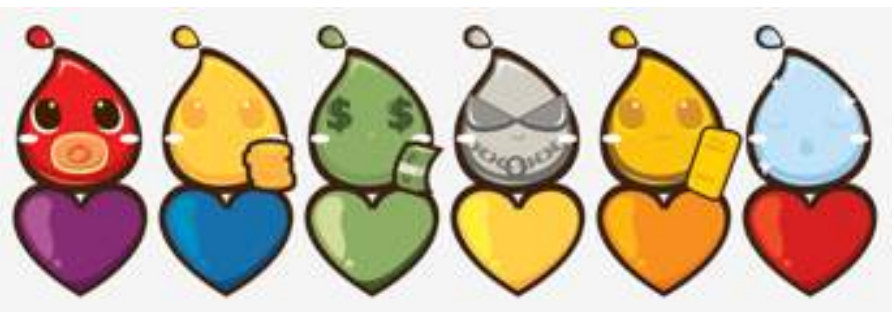

Fig. 7. Game4Life medals.

For every medal, there are tier badges to be unlocked before stepping up to the next level. Fig. 8 below is the design of stats list where all a user's achievement based total points earned from donation. This includes medals and unlockable backgrounds as well as lives saved and points earned. 


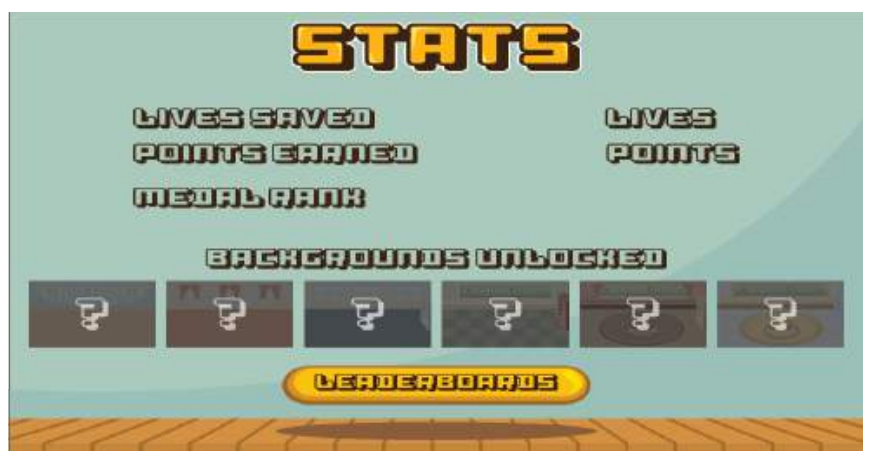

Fig. 8. Game4Life the design of stats list.

\section{F. Reward System}

Reward is the physical redemption of food vouchers or internet vouchers. For every time they donate the same amount of points will be added as reward credits and points earned. Points earned value always increases for each time they submit codes. Reward credit on the other hand is subtracted the total amount of reward price they wish to buy. Every reward has a price according with their value. Some rewards could be bought right away from their first donation and some need time from several donation points to be added up.

\section{IMPLEMENTATION AND TESTING}

\section{V.1 System Specification}

For implementing Game4Life system, these are the specification requirements:

\section{A. Server}

Game4Life is a hybrid mobile application in which most logic and workload are handled on the server. Most of the features require internet connection with the server. A reliable server with high availability or uptime is the most important thing to ensure users are able to access Game4Life any time. Redundant servers are highly recommended. A fast bandwidth connection is required to maintain multiple connections with users. Assuming there are large number of users, high volume of upload and download bandwidth are required. Unlimited bandwidth is preferable. The last hardware requirement is a minimum of $10 \mathrm{MB}$ disk space is required to store all users, comments and codes data on database.

The minimum software required on the server is: Unix Based Server with cPanel hosting control, Apache 2.0, PHP 5.4.7, phpMyAdmin 3.5.2.2, MySq1 5.1.

\section{B. Mobile device (Apple device)}

Here are the list compatible of Apple devices to run Game4Life properly iPhone (iPhone 3GS, iPhone 4, iPhone 4s, iPhone 5, iPhone 6, iPhone 6S), iPad (iPad, iPad 2, iPad 3rd Generation, iPad 4th Generation), iPod (iPod Touch 4th Generation, iPod Touch 5th Generation). To run this application, working GPS and internet connection are required and also iOS 4.3 minimum.

\section{V.2 Prototype Screen Shoot}

Below are several prototype screenshot examples from the Game4Life application.

\section{A. Interface}

The initial menu on Fig. 9 is the first menu that allows users to find some information, login and register.

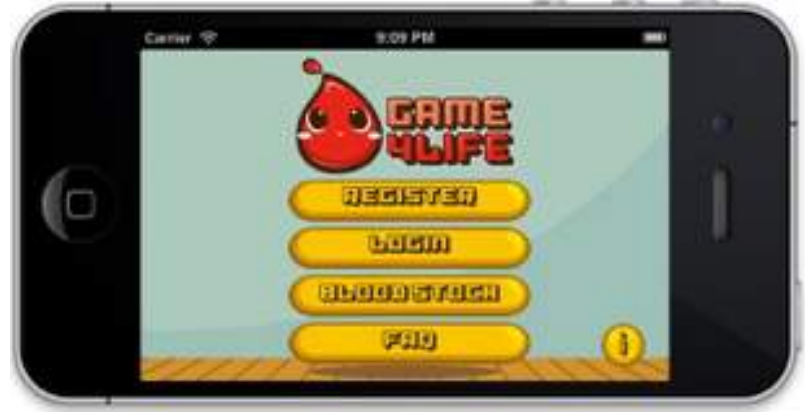

Fig. 9. Initial Menu Interfce.

\section{B. Blood Stock}

Below in Fig. 10 is the blood stock interface containing real time data updated from Google drive spreadsheet and fetched by Yahoo Query Language.

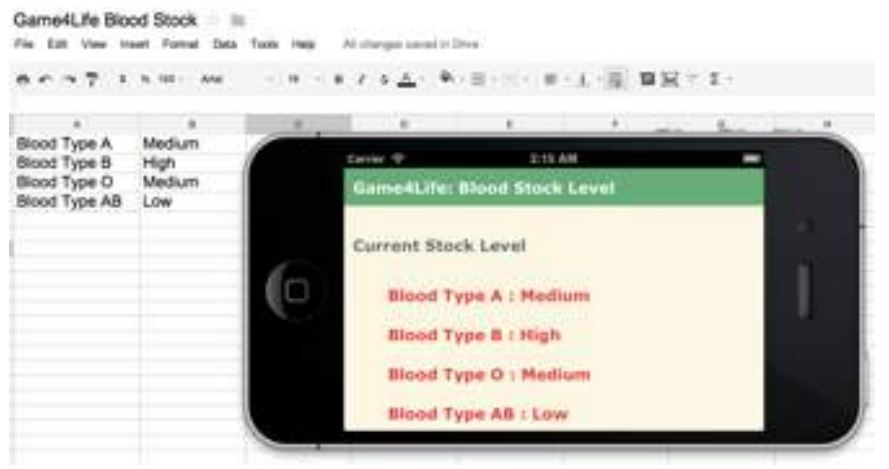

Fig. 10. Blood Stock.

\section{Frequently Asked Question}

The Frequently Asked Question feature on Figure 5.24 is available in both English and Bahasa Indonesia. Questions and answers are updateable online via Google Drive as the data uses Yahoo Query Language in real time, similar with the blood stock feature.

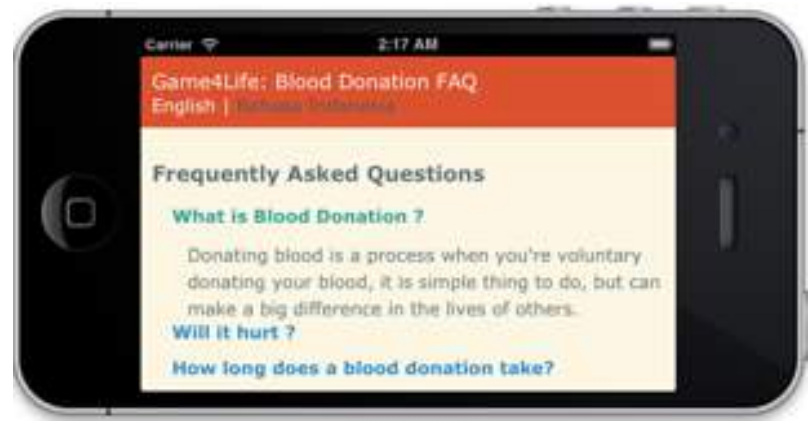

Fig. 11. Frequently Asked Questions. 
FAQ also has interactive features as calculating next donation as seen on Figure 5.25 for blood donors based on Palang Merah Indonesia standards in which 75 days are required between donations [27].

\section{Donation Calculator}

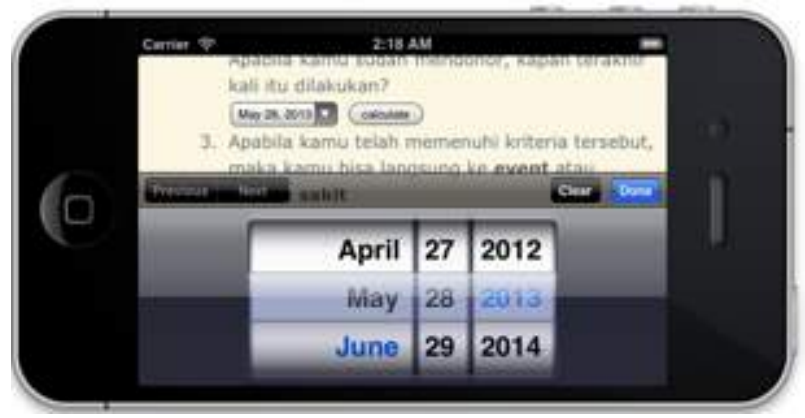

Fig. 12. Donation Calculator.

After the last donation input is processed the system will notify the user whether they are or not able to re-donate their blood as well as the date when they are eligible.

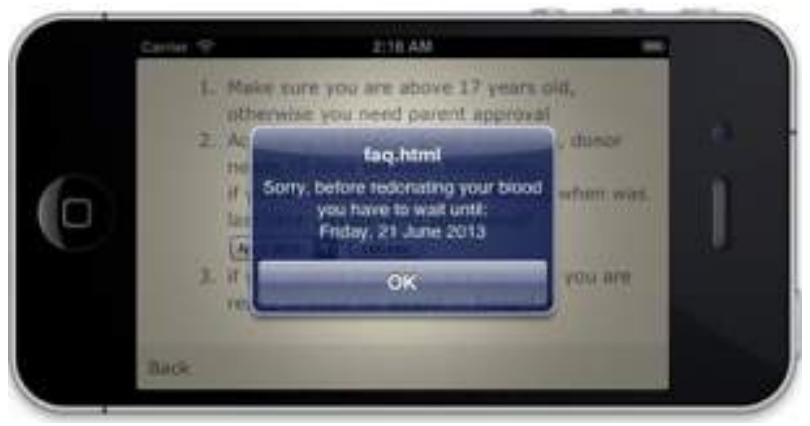

Fig. 13. Donation Calculator Result.

Fig. 13 above shows the notification example in which this user is not eligible to re-donate yet.

\section{E. Event Locator}

When there is blood donation event, users are able to check the location and follow the instructed directions. Game4Life Event Locator on Fig. 12 would integrate the user's device GPS to find user position and calculate the route to the event as shown on Fig. 14. It will be represented as both map and route instructions. The map is powered by Google Maps.

When the 'Event' button is pressed from menu Fig. 14, the user will be redirected to the Event Locator sub menu.

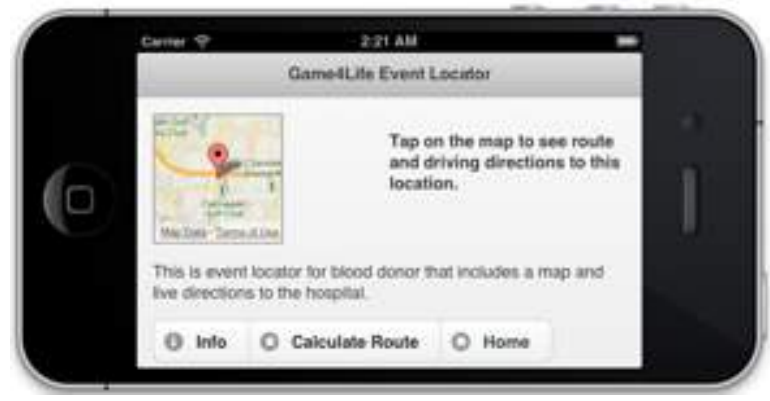

Fig. 14. Game4Life Event Locator Interface.
For this example the route is calculated from Binus University International to Rumah Sakit Fatmawati where the blood event is held.

\section{F. Reservation}

Reservation on Fig. 15 is one of the features that could be accessed from the main menu after a user logs in or is registered. This reservation feature will allow user to send email for submitting their enquiry to designated recipients or hospitals.

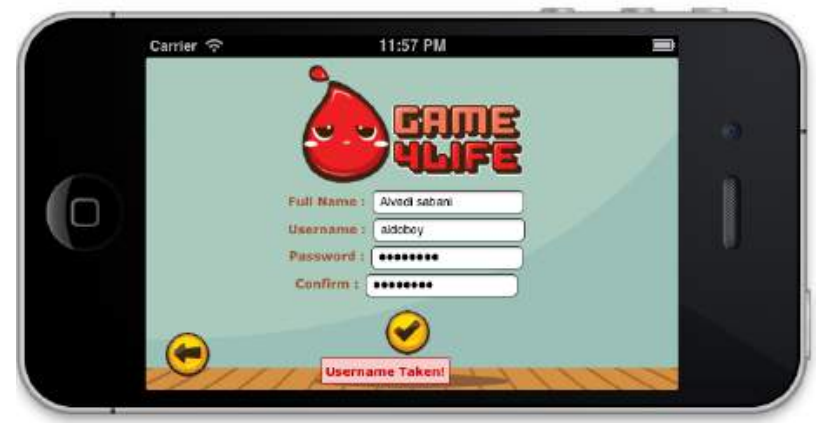

Fig. 15. Reservation System Interface

Here are the examples of possible recipients list of hospital as shown in a roll bar in Fig. 16.

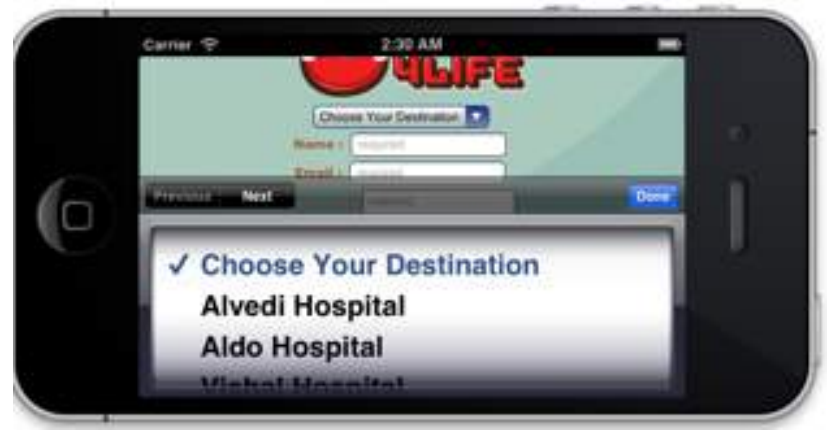

Fig. 16. Recipients List

When a user successfully submits their enquiry, the recipient will be notified through their email inbox as shown in Fig. 17

$\bigoplus$ New Reply $/ \vee$ Delete Archive Junkl $\checkmark$ Sweep $\checkmark$ Moveto $\vee$ Categories $\vee \ldots$ Game4Life hospital enquiry from sabani

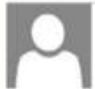

aldo@alvedi.com (aldo@alvedi.com) Add to contacts 3/29/2013 To: alvediefive.com *

I would like to donor Wed 15th May, Please Confirm Availability

Fig. 17. Game4Life Event Locator Interface.

\section{G. Game}

When a user enters the game world (hospital room), they can see the patient soon they could save after donating their blood. The orientation will be landscape as below in Fig. 18. 


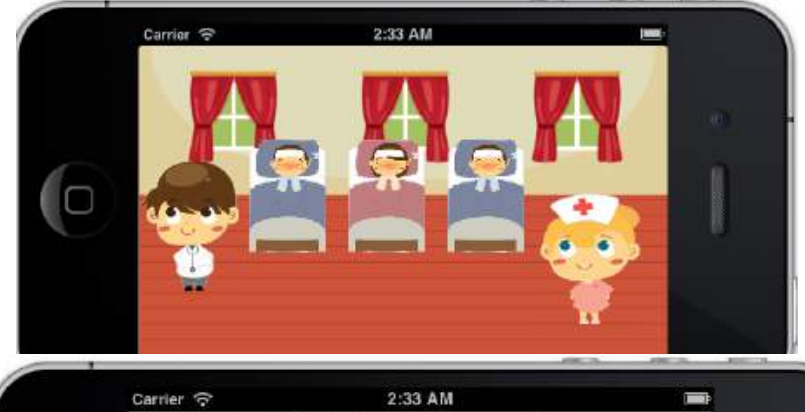

Fig. 18. Game Interface

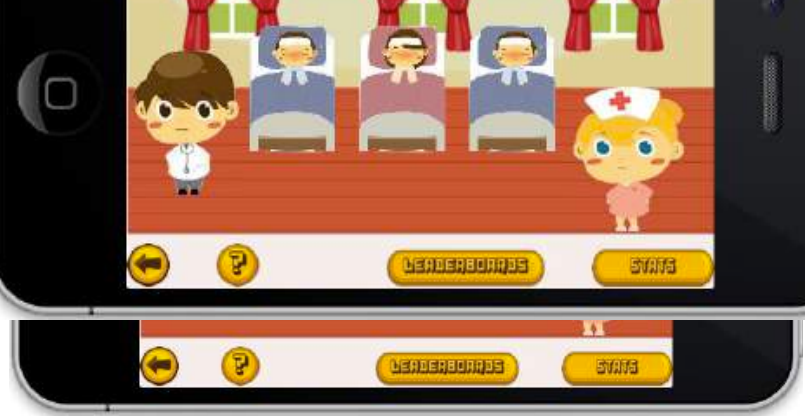

Fig. 19. Game Interface with all pop ups

As can be seen from above Fig. 19, the user could interact with both doctor and nurse. When the user interacts with the doctor, they could redeem the code they got after donating their blood to get points and progress in the game and with the nurse they can check their stats, leaderboard and instructions.

When a user is accessing the game for the first time, instructions will pop up and it can be re-accessed later from "question mark" or "?" symbol from the nurse as in Fig. 20.

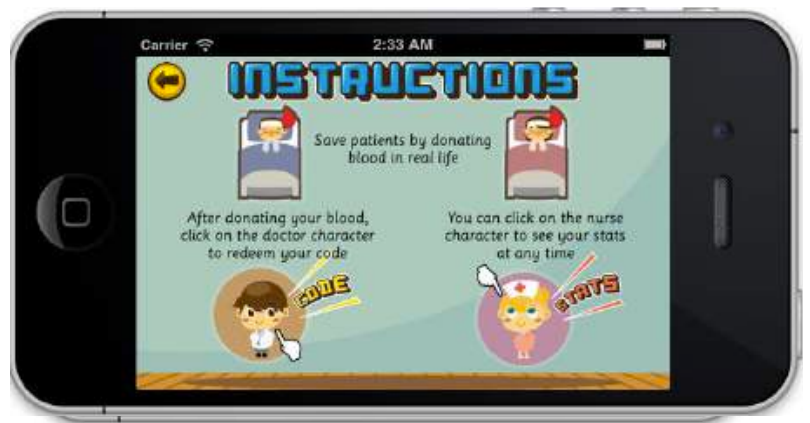

Fig. 20. Game Instructions

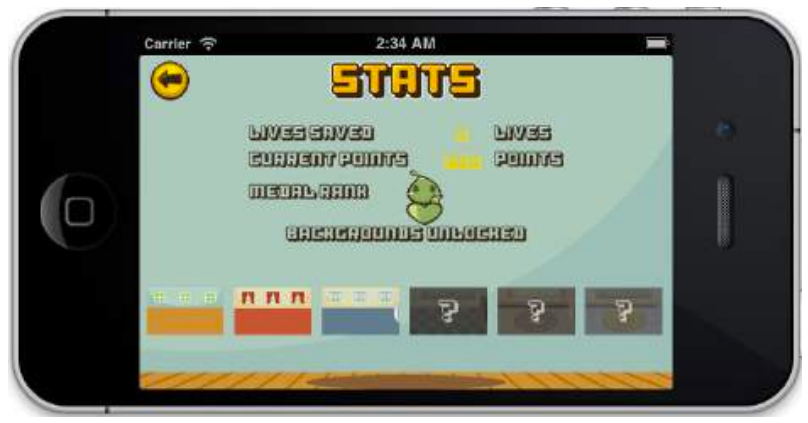

Fig. 21. Achievement Status
From stats on Fig 21, users are able to see their in-game rewards as unlocking backgrounds and medals. It also shows how many lives the donor has saved as well as their redeemable points to be exchanged on a catalogue.

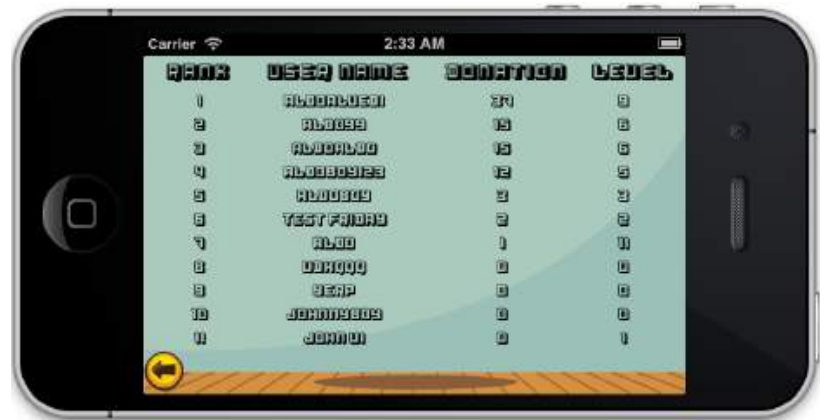

Fig. 22. Leaderboard

The leaderboard on Fig. 22 is a core part of the gamification implementation. It shows them their position compared with other players. The main purpose of this leaderboard is to engage them and encourage them to keep donating regularly and get their username on top.

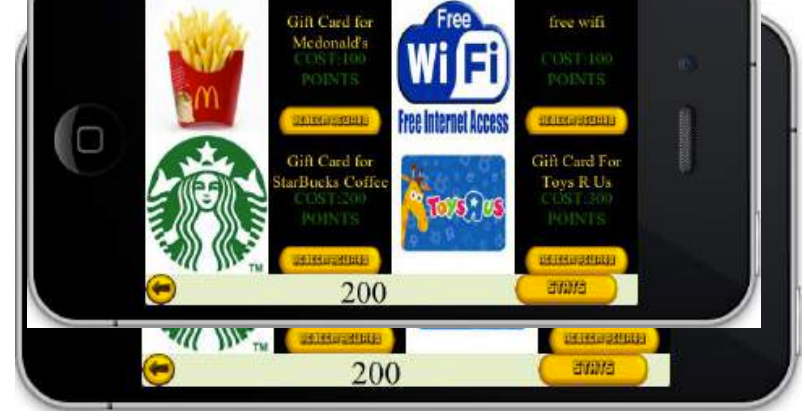

Fig. 23. Reward Catalogue

The reward catalogue as shown on Fig. 23 is the list of exchangeable rewards where donors could use their points to purchase them. When a designated reward is chosen, the system will pop up confirmation as seen in Fig. 24 for the user to confirm their decision because there is no refund in most scenarios once it is bought.

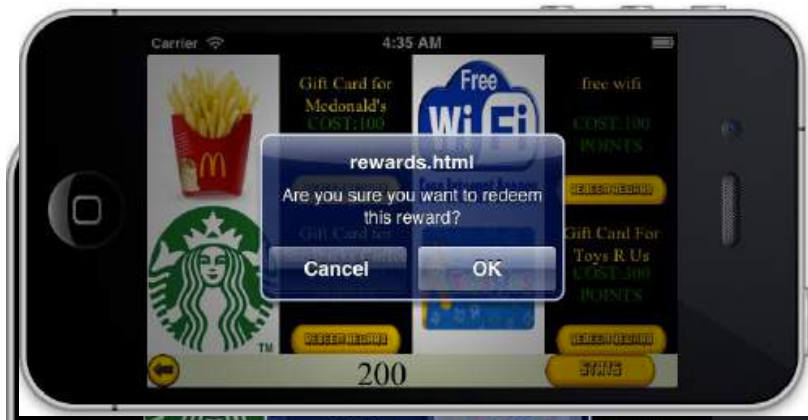

Fig. 24. Reward Confirmation

\section{H. Event Calendar}

The Event Calendar is a simple calendar where user could check upcoming blood donation events. With all the information in advance, hopefully it would help donors 
organize their schedule to participate in blood donation events. The interface is shown in Fig. 25 below.

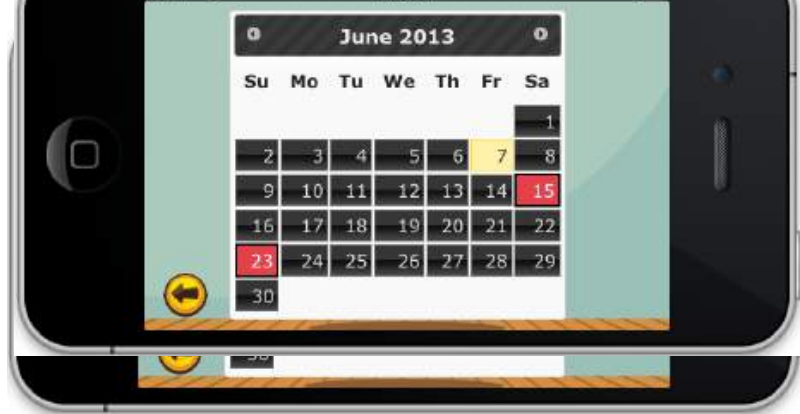

Fig. 25. Event Calendar Interface

The yellow dates in Fig. 25 shows today's date. Fig. 26 shows when an event date (indicated by red) is being clicked.

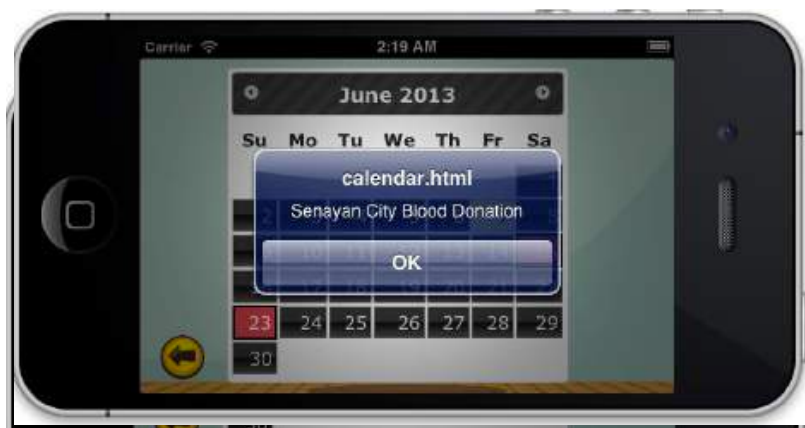

Fig. 26. Event Details

\section{V.3 Testing}

There are several requirements needed to be satisfied before testing and implementation could be conducted.

We decided to create precondition requirement list on Table 1 for reference on every corresponding test case.

Table 2 Precondition Requirements

\begin{tabular}{|c|l|l|}
\hline ID\# & Name & Description \\
\hline PR01 & Internet Connection & Internet connection is available \\
\hline PR02 & Web Service & Web service server is accessible \\
\hline PR03 & Database & Database on server is accessible \\
\hline PR04 & Logged in & User has been logged in to the system \\
\hline PR05 & GPS & Phone GPS is working properly \\
\hline PR06 & Google & Google Server is accessible \\
\hline PR07 & Yahoo & Yahoo Server is accessible \\
\hline
\end{tabular}

\section{a. Unit Testing}

Unit testing is the first testing phase which needed to be done to ensure components behave properly before they are integrated and compiled as a whole system. A huge amount of time can be saved by early finding of the source of defects in unit testing compared with fixing issues in later phases.

\section{b. User Acceptance Test}

The User Acceptance Testing was conducted individually for the user to fill the survey along with testing the application on the device. UAT becomes much faster. Here are some pictures of UAT when conducted in a university environment on Fig. 27.

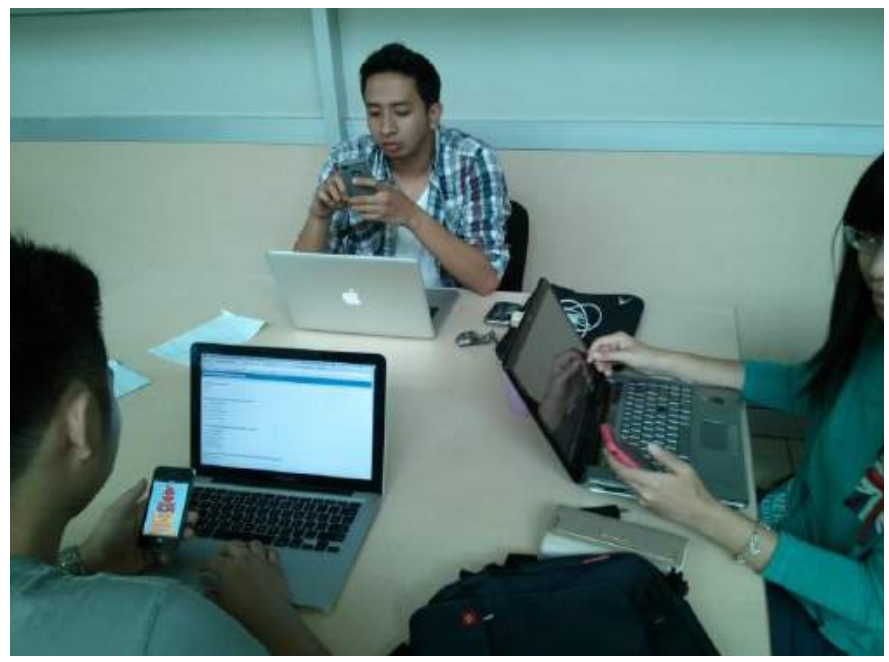

Fig. 27. User testing

\section{RESULTS AND DISCUSSION}

The first testing - self-conducting unit testing for function and feature application test - resulted in a pass for all components. Based on this result we continued to conduct the second testing: User Acceptence Test.

Based on the second testing, we collected UAT results from 62 participants. The UAT with pilot test to enhance the validity of questions and quality of the survey took about a week and half, here are the results as follows.

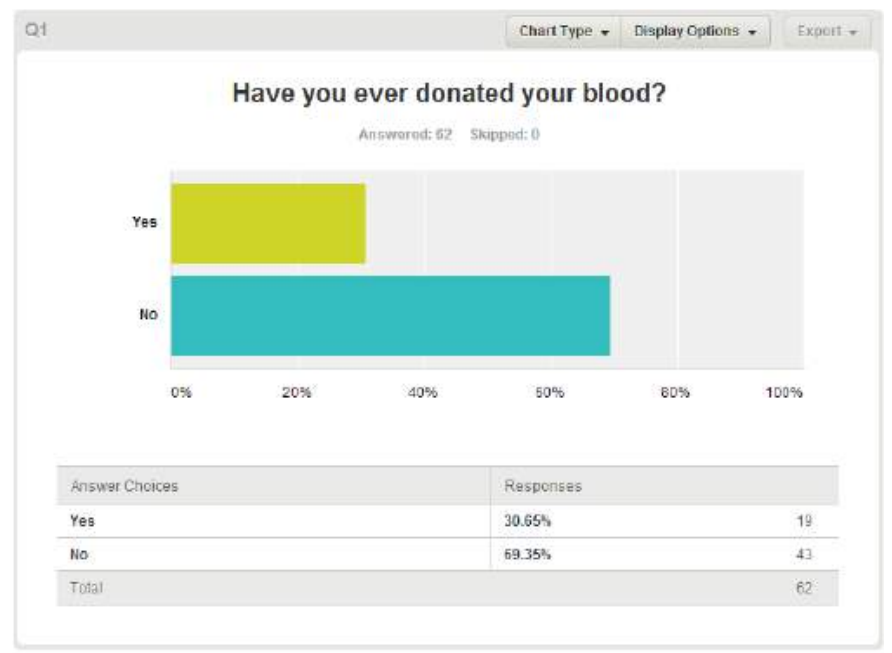

Fig. 28. UAT Question 1

The first question is about categorizing the participants whether they are blood donors or not. Instead of age and gender, this is the only relevant question for categorizing participants as we only distributed survey to people whose ages qualified them for blood donation.

The main objective of this question is to determine and analyze how the deliverable prototype is useful for non-blood 
donors or future donors and blood donors. Our aim is to develop a mobile application that helps blood donor schedule their donation and engage them with a reward system as well as encourage future donors to become one, so it is really important to access their opinions and satisfaction of our prototype for this matter.

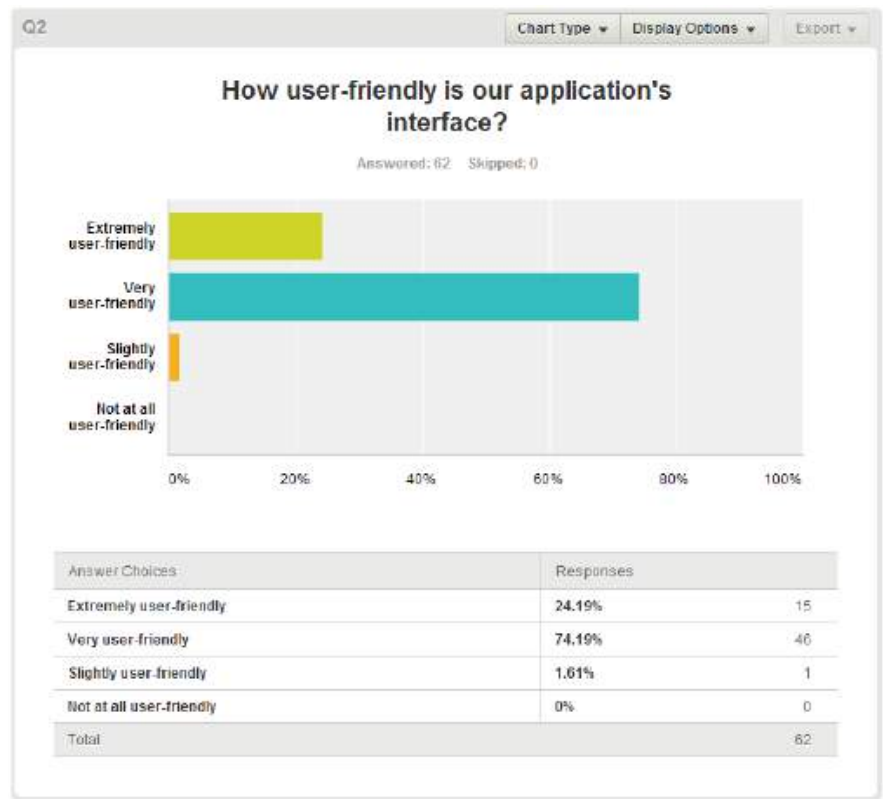

Fig. 29. UAT Question 2

The second question focused on user friendless of our mobile application interface. The user interface is one of the most important aspects for software success. Bad user interfaces drive users to give up on the application. As the result of the survey, most participants decided that Game4Life has a clean ease of use user interface.

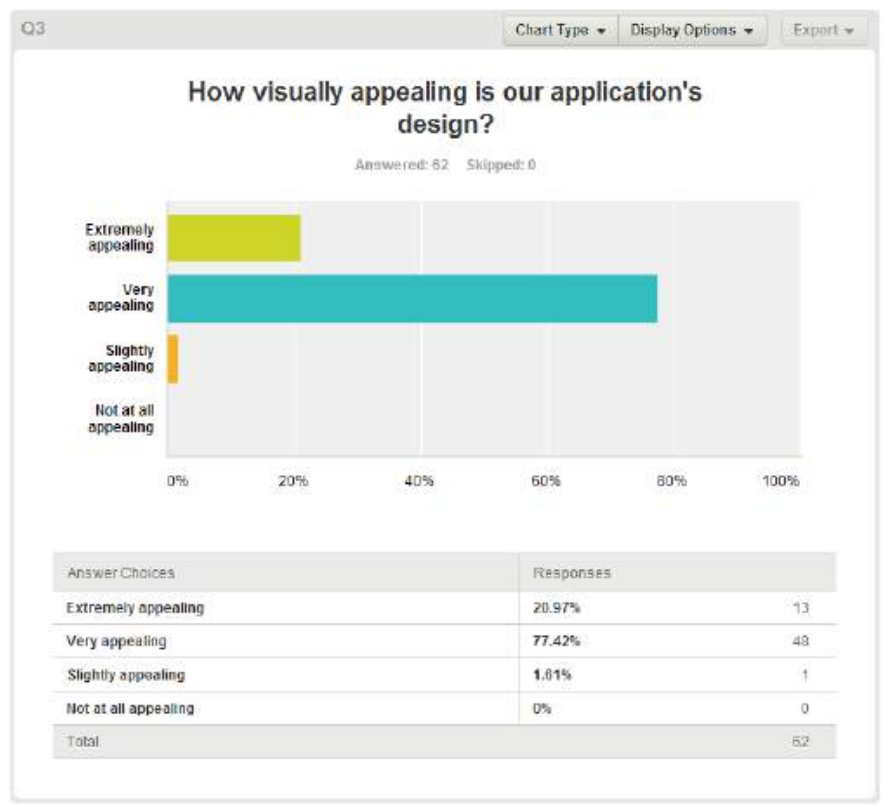

Fig. 30. UAT Question 3
The third question is about the interface's graphical design. This question was about to be dropped before the pilot test for the survey. However, based on self-research and informal discussion with prior participants for pilot tests, aside from user friendless of the interface, graphical design is also a key point because before we could engage users on gamification features as reward system and achievement, we need them to stay on our application and dig further into the features. So as the initial interest point would be an appealing design, we decided this question is important to be included and accessed.

Based on on the result, question two and three are related which means both user friendless and appealing design are really important to have a good user interface. The fourth question focused on Game4Life features in general and gamification implementation, and how it is useful for them. Along with this survey, participants checked every feature while filling them accordingly.

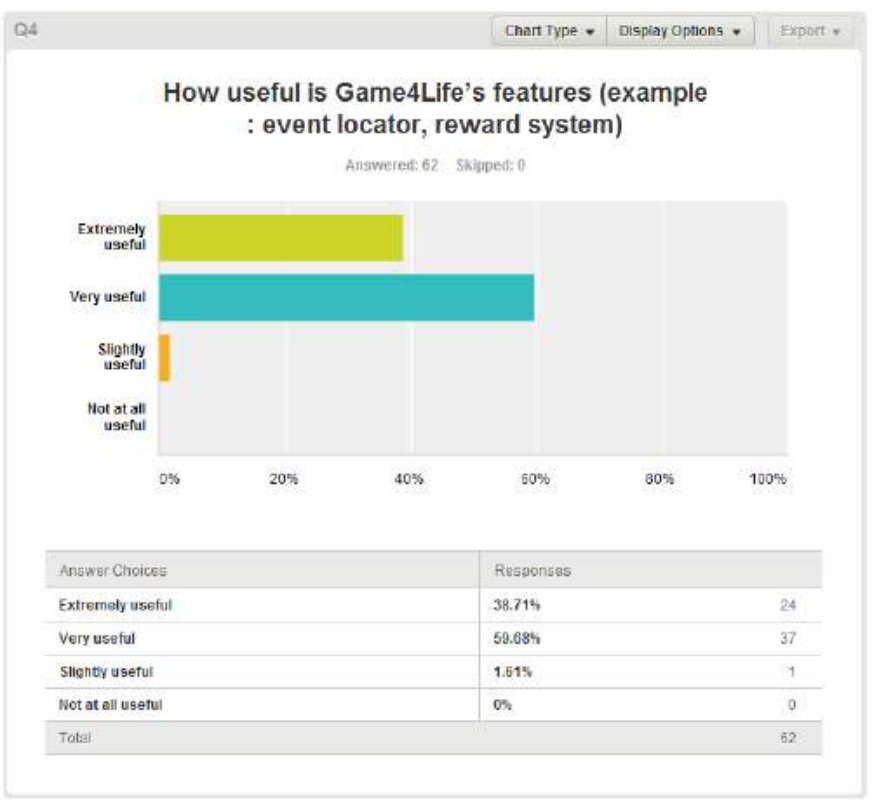

Fig. 31. UAT Question 4

The fourth question showed that the responses are extremely positive. 


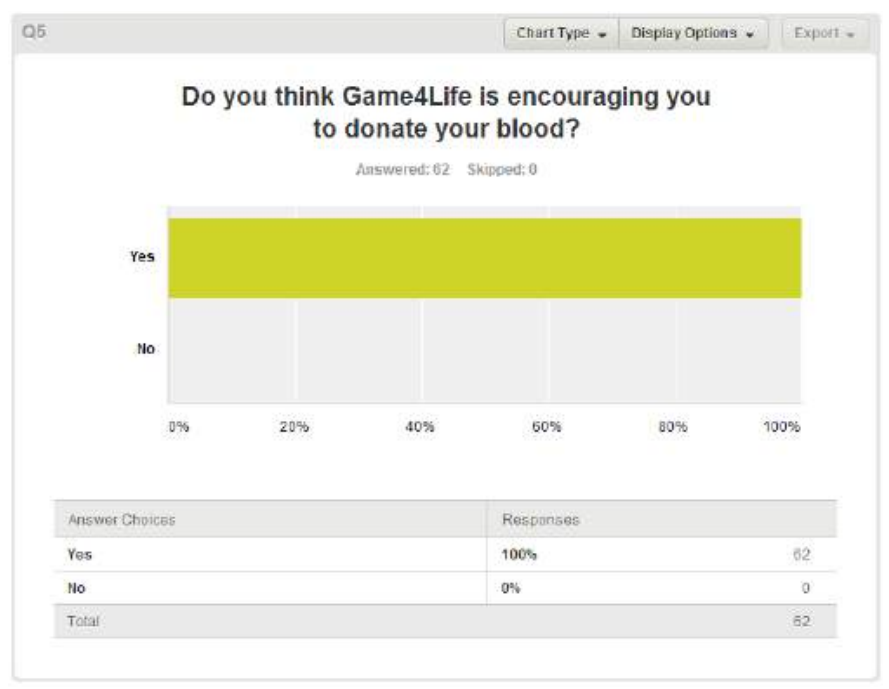

Fig. 32. UAT Question 5

The fifth question our survey is the key question to determine the success of our aim to encourage users to donate their blood. In a surprising result, all the participants felt that Game4Life encouraged them to donate blood which means our main aim has been successful.

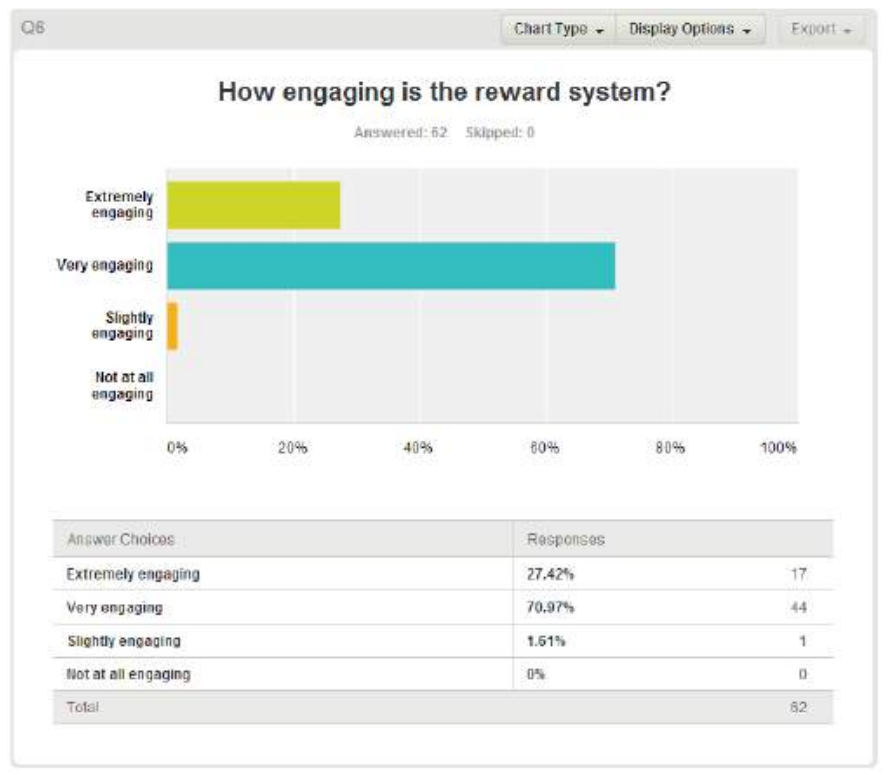

Fig. 33. UAT Question 6

The sixth question is about determining how significant gamification implementation is as a reward system to engage them to keep donating their blood regularly, collecting the points and exchanging them for the reward. The results show that most of the responses are positive. It can be concluded that gamification implementation as a reward system is successful. Thus once again our aim has been successful.

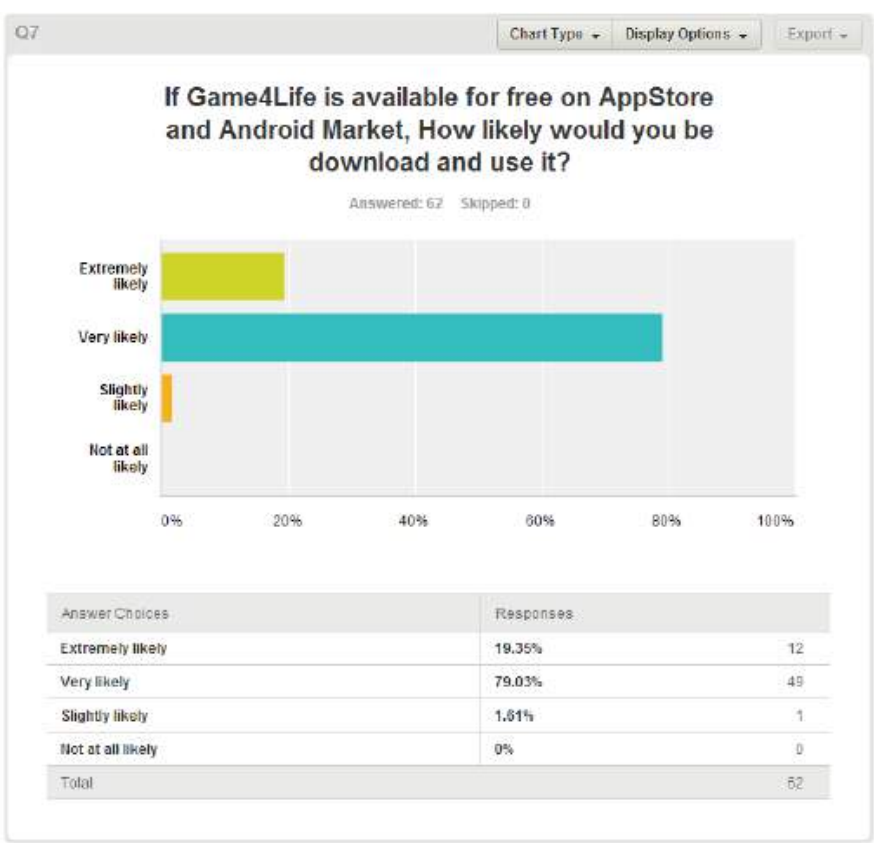

Fig. 34. UAT Question 7

The seventh question focuses on the prospects of the software once it is ready to be implemented and launched. As seen from the results most participants are willing to download and use Game4Life once it is available which means Game4Life is viable to be implemented in real life.

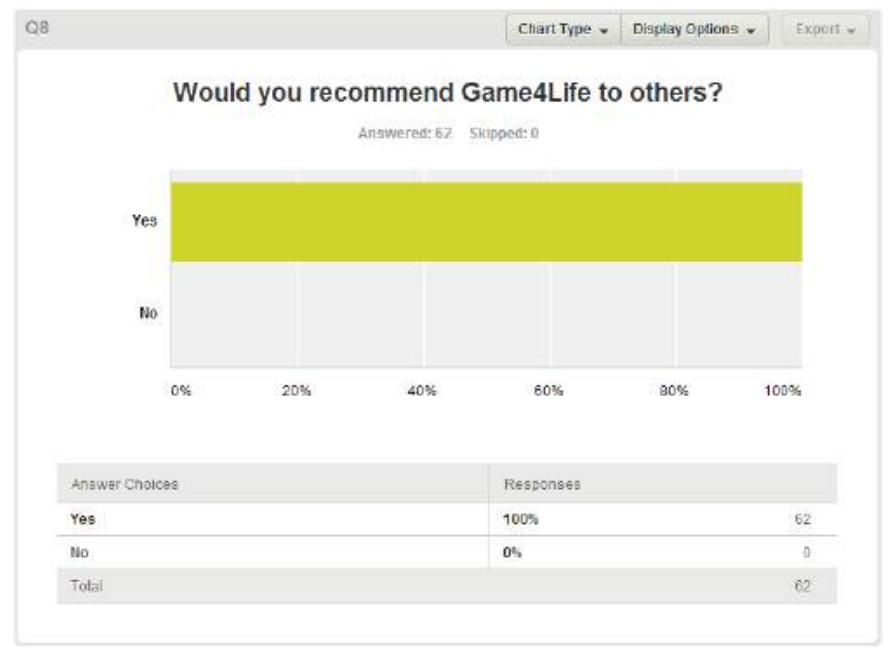

Fig. 35. UAT Question 8

The eighth question aimed to determine whether or not they would recommend Game4Life to their family, friends and acquaintances. For early implementation, word of mouth marketing is really important for a start up to popularize the application. Based on the results Game4Life has a promising market spread and hopefully this would happen during the early stages of implementation. It is important to have as much user responses as possible on the development and lifecycle of the application. 


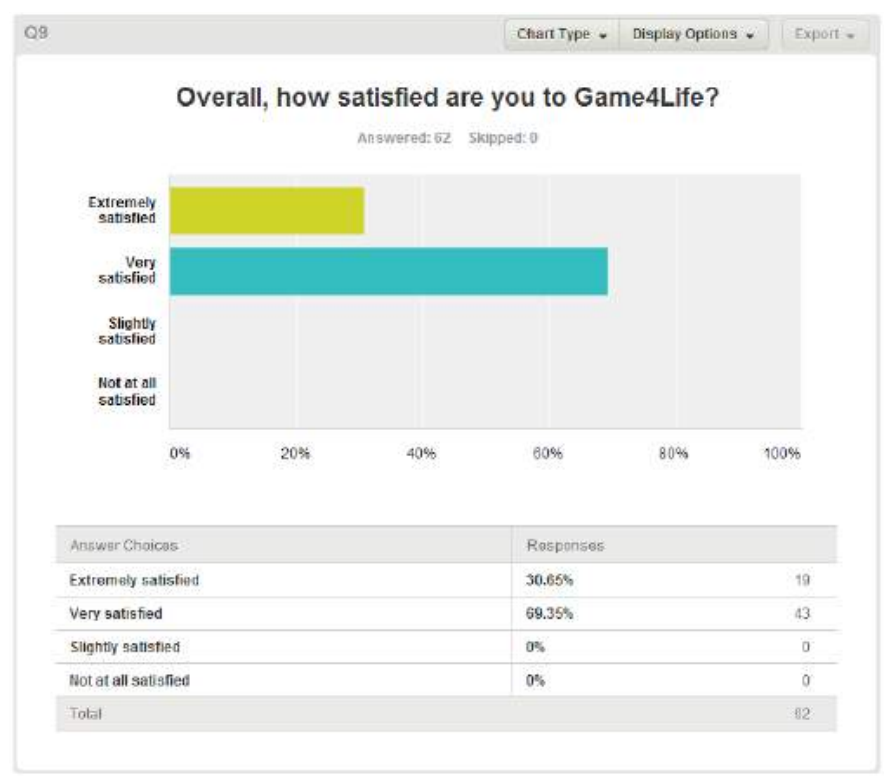

Fig. 36. UAT Question 9

The ninth question is related with the last two questions. It is all about the users' satisfaction. However this question still needs to be included for reference data to analyze their satisfaction. As it is related with the two previous questions, the result is also positive. The last question is an open answer for participant to write feedback as comments and suggestions to improve the mobile application. Most of the suggestions are related to the user interface where they prefer to have all the screens in landscape. Thus, we redesigned the interface to landscape.

\section{CONCLUSIONS AND RECOMMENDATIONS}

Gamification is currently developing and becoming more popular as it is being used widely. The term was first used in $2002 / 2003$, and it became more popularly used in 2010 [28]. Most of the gamification is being use for commercial purpose currently. This thesis is implementing gamification for a social purpose to support blood donation shortage as its main purpose.

Based from unit testing to system testing results, the deliverable prototype of this thesis development has satisfied its scope and requirements both functionally and nonfunctionally. The results indicated good user satisfaction and Game4Life has fulfilled its main aim to encourage future donors to donate their blood for the first time and provide features to help donors schedule their next donation. It is concluded that Game4Life has been successful satisfying its scope and requirements.

For this mobile application system to be implemented in real life, a cooperation of agreement with Palang Merah Indonesia, company partners and hospitals needs to be established. Further discussions, proposals and legal documents need to be arranged.

Aside from that, several improvements can be developed for a Game4Life web service and some features could be added to the mobile application, but cannot be implemented now due to time constraints.

\section{A. Web Service}

Several improvements can be done on the web service:

(1) More reliable server: Game4Life currently is using a free web server to host the database and logic handler. It is good enough to handle prototypes and testing at the current stage. However, for the future implementation, higher uptime, and more bandwidth server is required to provide a reliable service.

(2) Back-end graphical user interface: Instead of cPanel, a more user-friendly back-end management system for an administrator needs to be developed. With a graphical user interface it will become easier to maintain and keep track of data.

\section{B. Mobile Application}

Some useful features on mobile application could be added to the future improvement such as:

(1) Hospital Locator: Reusing the event locator, a hospital locator could be developed. By listing all hospitals on the map database and users will be able to select a destination hospital and the system calculates the route.

(2) Grand Prize Reward: Aside from reward catalog by exchanging points, Game4Life could draw grand prize once a month or regularly for lucky users. The draw is random to users that donated their blood during the respective period of time.

(3) Regular donor bonus: When a donor donates their blood regularly within a timeframe they are eligible for bonus points. This feature will engage regular donors as they will not miss the bonus points given.

(4) Social Media Integration: Integration with social media as simple as upload achievement medals to Google+, Facebook and twitter would be a good option to develop as it will also advertise blood donation and Game4Life among a user's circle.

\section{REFERENCES}

[1] A. Dongen, R. Ruiter, C. Abraham, and I. Veldhuizen. (2014, March) Predicting blood donation maintenance: the importance of planning future donations. Wiley Online Library:Transfusion [Online] Vol: 54, Issue: 3: Pages 821-827.

Available: http://onlinelibrary.wiley.com/doi/10.1111/trf.12397/full

[2] Republika Online. (2013, February) Jumlah Pendonor Indonesia di Bawah Malaysia dan Singapura | Republika Online. [Online]. http://www.republika.co.id/berita/nasional/umum/13/02/18/mif9kcjumlah- pendonor-indonesia-di-bawah-malaysia-dan-singapura

[3] I. Sherr. (2016, August) Pokemon Go -- away: Players are ticked off at world's most popular game | cnet.com. [Online]. Available: http://www.cnet.com/news/pokemon-go-away-players-are-ticked-off-atthe-worlds-most-popular-game/

[4] A. Baidya . (2016, February) iPhone vs Android Smartphone Sales 2015: Apple Wins Yet Loses [REPORT] II dazeinfo.com. [Online]. http://dazeinfo.com/2016/02/11/apple-iphone-android-smartphone-sales2015-kantar-report/ 
[5] G. Zichermann and C. Cunningham, Gamification by Design: Implementing Game Mechanics in Web and Mobile Apps., 1st ed. Sebastopol, California: O'Reilly Media, 2011.

[6] K. Huotari and J. Hamari, "Defining Gamification - A Service Marketing Perspective," in Proceedings of the 16th International Academic MindTrek Conference 2012, Tampere, Finland, October 3-5., Tampere, 2012, pp. 2-4.

[7] K. Robsona, K. Planggerb, J. H. Kietzmanna, I. McCarthya, L. Pitta. Is it all a game? Understanding the principles of gamification. ScienceDirect: Business Horizons Volume 58, Issue 4, July-August 2015, Pages 411-420

[8] J. Hamaria, and J. Koivistoa. Why do people use gamification services?. Elsevier: International Journal of Information Management. Volume 35, Issue 4, August 2015, Pages 419-431

[9] J. Hamari, J. Koivisto and H. Sarsa, "Does Gamification Work?-A Literature Review of Empirical Studies on Gamification", System Sciences (HICSS) 2014 47th Hawaii International Conference on, pp. 3025-3034, 2014.

[10] A. Matallaoui, P. Herzig and R. Zarnekow, "Model-Driven Serious Game Development Integration of the Gamification Modeling Language GaML with Unity", System Sciences (HICSS) 2015 48th Hawaii International Conference on, pp. 643-651, 2015.

[11] Gamespiel. (2011, April) Gamification: Toeing the fine line between Flirting with your Hot Cousin and Kissing your Sister! - Gamespiel. [Online]. http://gamespiel.typepad.com/my-blog/2011/04/gamificationtoeing-the- fine-line-between-flirting-with-your-hot-cousin-and-kissingyour-sister.html

[12] T. Stierman. (2012, February) Gamification is de nieuwe marketing hype - the social conference. [Online].

http://www.publishr.nl/2012/02/the-social- conference-gamification-isde-nieuwe-hype-tsc12/

[13] S. Costello. (2016, June) How Many Apps Are in the iPhone App Store?|about.com.[Online]. http://ipod.about.com/od/iphonesoftwareterms/qt/apps-in-app-store.htm

[14] C. George. (2009, October) American blood donations | GDS Publishing. [Online]. http://www.executivehm.com/news/blooddonations/

[15] PMI Cabang Surabaya. (2004) Unit Transfusi Darah PMI Cabang Surabaya. [Online]. http://www.pmiutdsby.org/donor.php
[16] American Red Cross. (2013) Donation FAQs | American Red Cross. [Online]. http://www.redcrossblood.org/donating-blood/donation-faqs

[17] Australian Red Cross. (2012) Frequently Asked Questions | Australian Red Cross Blood Service. [Online]. http://www.donateblood.com.au/faq - faq 314

[18] D. Reisinger. (2013, January) Apple App Store hits 40 billion downloads; 20 billion in 2012, alone | Apple - CNET News. [Online]. http://news.cnet.com/8301-13579 3-57562400-37/Apple-app-store-hits40-billion-downloads-20-billion-in-2012-alone/

[19] NZ Blood. (2016, August) Smartphone App for Donors / Give blood / NZBLOOD - NZ Blood Service. [Online]. http://www.nzblood.co.nz/Give- blood/Smartphone-App-for-Donors

[20] Nebraska Community Blood Bank. (2013) There‘s An App For That! ncbb.org. [Online]. http://www.ncbb.org/news/there's-app

[21] BloodyHelp, Inc. (2016) BloodyHelp's Official Page. [Online]. http://bloodyhelp.com/

[22] E2M. (2016) Entertainment to Mobile Official Website | Main Page. [Online]. http://www.e2mobile.org/

[23] Blood Buddy. (2016) Blood Buddy. [Online]. http://www.bloodbuddy.com/en/

[24] Apple Inc. (2016) SG Blood for iPhone, iPod touch and iPad on the iTunes App Store. [Online]. https://itunes.apple.com/tn/app/sgblood $/ \mathrm{id} 301980124 ? \mathrm{mt}=8$

[25] University of Maryland Medial Center. (2012, December) Why People Don"t Give Blood | UMMC Blood Drive. [Online]. http://www.umm.edu/blood/why-people-do-not-donate-blood.htm

[26] B. Serviss. (2013, January) How Gamifying Blood Donations Can End the Shortage. [Online]. http://www.dashjump.com/gamification-blooddonation- shortage/

[27] Sam. (June, 2009) The importance of user interface and why it is critical to your success online - WebLog | bwired. [Online]. http://www.bwired.com.au/blogs/digital-web-strategy/the-importanceof- user-interface-and-why-it-is-critical-to-your-success-online

[28] Zac. (2013, January) A brief history of gamification | zefcan.com. [Online]. http://zefcan.com/2013/01/a-brief-history-of-gamification/ 